\title{
The Use of Early Recollections in Adlerian Psychotherapy: Evidence in Neuroscience Research
}

\author{
Iris Lavon ${ }^{1,2 *}$ and Rachel Shifron ${ }^{1 *}$ \\ ${ }^{1}$ Adler Institute, Israel \\ ${ }^{2}$ Gaffin center for Neurooncology, Hadassah Hebrew University Medical Center, Israel
}

Submission: June 23, 2020; Published: August 10, 2020

*Corresponding author: Dr. Iris Lavon, Hadassah Hebrew University Medical Center, PO Box 12000, Jerusalem 91120, Israel; Dr. Rachel Shifron, Adler Institute, Kfar Saba, Israel

\begin{abstract}
This review addresses the effective and necessary use of early recollections in Adlerian psychotherapy and the support for this technique found in neuroscience research. We show in this review that the use of early recollections is essential in psychotherapy, not only for understanding the person's personality but also for triggering movement and change, through the process of reconstruction and reconsolidation of early recollections-all validated in the latest neuroscientific research. Although this review is focused on the use of early recollections in Adlerian psychotherapy, we are convinced that every psychotherapist should be exposed to the important new information found about memories and early recollections.
\end{abstract}

Keywords: Early recollections; Brain plasticity; Reconstruction of early recollections; Reconsolidation of early recollections; Metaphors

\section{Introduction}

The main purpose of this paper is to present the latest neuroscience research in support of the use of early recollections (ERs) during Adlerian psychotherapy. We are convinced it is essential that every psychotherapist be exposed to this important new information about memories and ERs. The theory of Alfred Adler (1870-1937), founder of the individual psychology, is holistic, looking at the individual as a thinking, feeling, creative, active, and social human being. Therefore, every individual has the creative power to move towards, connect with, contribute to and be useful to, others. Adler's theory is a theory of movement, the goal of which is to enable change, growth, personal development, and flexibility, which are all needed to cope and deal with the demands of life.

Miller \& Taylor [1] recently examined Individual Psychology from a neuro-scientific perspective. They presented neuroscientific research relating to basic Adlerian concepts such as social embeddedness, early childhood experiences, purposefulness of behavior, development of Lifestyle and holism. This article addresses the effective and necessary use of ERs in Adlerian Psychotherapy and the support for this technique found in neuroscience research. It emphasizes three main ideas: firstly, the ER as a metaphor for current perspectives and feelings; secondly, the "self" of the person being comprised largely of his or her memories; and thirdly, reconstruction of ERs presenting a golden opportunity for holistic movement and change in Adlerian therapy.

\section{Discussion}

\section{Early recollections (ERs) in adlerian psychology}

One of Adler's most creative ideas was to identify the powerful potential for the use of ERs in psychotherapy. "Among all psychological expressions, some of the most revealing are the individual's early memories" [2] p. 351). The use of ERs is vital for the analysis of the client's unique pattern of movement, his or her Life Style. Early recollections are Life Style metaphors, a creative way of accurately describing a client's current emotional state. The metaphoric language is essential for the development of a common language between the therapist and the client.

“Memories are important only for what they are 'taken as'; for their interpretation and for their bearing on present and future life" (Adler, 1956, as cited in Ansbacher \& Ansbacher, [2] p. 352). We do not believe that all early recollections are a correct record 
of actual facts. Many are even fanciful, and most are changed or distorted at a later time, after the events are supposed to have occurred but this does not diminish their significance. "It must be remembered that old remembrances are not reasons, they are hints" (ibid., p. 353).

Early recollections as metaphors provide an excellent tool for identifying a client's strengths and creative abilities [3-5]. In the therapeutic process, discovering strengths enables the client and the therapist to reconstruct ERs and find creative, productive solutions to cope differently with life. Recollections and dreams are primarily unique, creative productions of the individual According to Adler [2]: "They are selections, distortions, or innovations of past events by the individual to fit his [her] underlying mood, purpose, and interests and would change accordingly if not in respect to content, at any rate in respect to feeling tone" (p. 350).

Neuro-scientific research has demonstrated this is the exact process that takes place in the brain, as discussed in the next section. Therapists use ERs to emphasise a person's ability to search for and choose alternative methods for dealing with the situations described in the ERs. Adler's reason for going back to the person's childhood was to obtain, as he said, a simpler picture of the style of life. It was, therefore, irrelevant to him whether memories were real or imagined or from an earlier or later period. In any event, they express the basic attitude that remains relatively constant throughout the years. "This is why Individual Psychology attaches great importance to the understanding of the earliest childhood recollections and it has shown that they represent revealing signs from the period when the style of life was constructed" (ibid, p. 289).

Each ER contains all the basic concepts of Adlerian theory:

Holism.: Every ER is a whole metaphor. It describes creatively the person's thoughts, wishes and feelings about his or her life at the present time.

Movement: ERs are metaphors or stories in constant movementand can change over time. At each stage of development, the individual will describe the memory, or the feeling associated with the memory in a distinct way.

Belonging and social interest: Individuals target their movements to achieve the goal of belonging and actualising an authentic high level of social interest in family, work and society. This goal can be easily identified in each ER.

Creativity: Adler said every person is born with tremendous creative power, and every ER is a creative method for describing the individual's perceptions and feelings at the present time. "Memory is an artistic ability which conforms to the style of life of an individual. The impression as a whole includes much more than the experience which has been clothed in words" [2], p. 214).
Strategies and change of strategies to achieve the goal of belonging: The creative individual chooses effective strategies to ensure feelings of belonging. These strategies become the person's "private logic" and include his or her perception about self, life and others. The use of ERs enables the therapist to point out strategies that were intended to achieve a sense of belonging in the past but that may be less productive in the present.

Early recollections provide a "goldmine" of information. The therapist uses the ERs to identify the strengths and creative abilities of which the client is completely unaware because of the pain associated with them. Through looking at each ER, the therapist and the client can together identify productive strategies, those used in the past to ensure feelings of worth and belonging. These can then be assessed to determine whether they are useful or harmful in the present. It is essential for psychotherapists to understand the role ERs play in the client's Lifestyle. Change occurs in therapy when the therapist encourages the client to reconstruct the metaphor or ER and to tell the story in various new ways to induce new feelings. Adler referred to this process as reconstruction of ERs (discussed in a later section). The use of ERs enables the therapist to understand the client from a holistic point of view. To comprehend fully our use of the holistic concept, it is important to consider and understand brain processes.

\section{Memories in brain research}

"The self is essentially a memory, or more accurately, a set of memories" [6], p. 299). If we translate this quote into Adlerian language, one's Life Style or private logic is therefore essentially a chosen set of memories. The human brain is composed of over 100 billion neurons. Each neuron may connect to up to 10,000 other neurons, passing signals to each other via as many as 1,000 trillion synaptic connections to form neural networks. The essential function of these neural networks is to receive, store and process information from the environment, to integrate this data with previous information and to respond with appropriate adaptive behaviour [7]. This active process can be referred to as learning and memorizing, which occurs mostly at the synapsis level. The brain never stops changing through learning. The ability of the mind to change the structure and strength of synaptic connections is collectively referred to as brain or synaptic, plasticity. Throughout life, different experiences continuously restructure these synapses and ultimately shape individuals with unique memories, thoughts, skills and Life Styles.

Accordingly, it can be postulated that the biological memories are represented by vastly interconnected networks of synapses in the brain [8]. "Changing our mind" or, from an Adlerian point of view, making our private logic more flexible involves changes in the synaptic weight matrices of relevant neural circuits by strengthening or weakening existing synapses, making new synapses, or dismantling old ones. It includes changes in the 
intrinsic properties of neurons. These changes alter neural circuit function in information processing and ultimately cause behavioral changes that enable better adaptation to a changing environment [9]. Consequently, with each new experience and each remembered event or fact, the brain slightly rewires its physical structure and influences our behavior and feelings accordingly, as though our behaviour and feelings were also rewired.

\section{Holism and movement in therapy and neuroscience}

According to Adlerian Psychology, individuals' perceptions about themselves, others and life in general are shaped in their first five years of life, guided by their striving towards the ultimate goal of humankind: a sense of belonging. Following early experiences, the child develops creative strategies to overcome obstacles and adjust to the world of social relations [2]. Childhood experiences and associated creative strategies are mainly stored in synapses for long-term use and create the individual autobiographical memory defined as "memory for the events of one's life" [10]. The role of autobiographical memory in personality development is to maintain a coherent sense of self over time that will be used throughout life as an infrastructure to cope with life challenges.

Why are some experiences stored in long-term memory and the majority forgotten? Kant noted: "Recalling the past occurs only with the intention of making it possible to foresee the future" [11] (p. 79). Thus, according to him, one remembers only the events important for one's future. According to McGaugh [12] in his article, "Making Lasting Memories: Remembering the Significant", we remember in detail experiences that elicited emotional arousal. This specificity indicates that the body uses emotional stimulation to remember experiences important for its future. For instance, human children depend on their parents and others for survival, and their inherited capacities can develop only in society. A child wrapped in its mother's arms feels protected and loved. The hug triggers the release of oxytocin, as well as other hormones. Oxytocin is a neuropeptide, which promotes feelings of devotion, trust and bonding. Throughout an individual's life, on recalling this pleasant memory, he or she will strive to restore the enjoyable feeling that oxytocin had produced.

Adler's theory is teleological in the sense that human motivation, emotion and action are goal-directed. Adlerians postulate that human motivation and emotion stem from goals and strategies that the individual develops to ensure a feeling of belonging. Another example is the hormone dopamine, released when striving towards a goal. In the Stone Age, people might have been elated to find a fig tree. This excitement had a purpose: because the fruits were a source of available energy and important for survival, the people remembered where to find the tree the following year. When one strives for something, the brain secretes dopamine into certain circuits to reinforce the action - similar to the sweet taste of the fig - and increases the likelihood that the action will be repeated in the future.
Dopamine is also secreted when a child receives positive feedback, and therefore it is necessary to encourage and motivate him or her. It is no less important for human interactions in the adult's life, within relationships, in the world of work and among friends. Humans will use creative methods to feel encouraged. Encouragement is a necessary "nutrition" for the soul's survival. Like the fig tree, encouragements are memories that induce emotions because they are essential for human survival. In both cases, dopamine (also termed "the striving hormone") is secreted and motivates movement towards the nutrition - the fig or the encouragement. How does emotional arousal help store the memory for the long term? During unpleasant or aversive, as well as pleasurable, events [13], the brain signals to the adrenal glands above the kidneys to release the stress hormones adrenaline (epinephrine) and cortisol. The levels of these hormones increase while memories are undergoing consolidation. The release of adrenal stress hormones activates the amygdala, among other brain regions, which regulates memory consolidation by influencing information storage in brain regions such as the hippocampus and prefrontal cortex. These interactions increase the likelihood that emotional events will be consolidated into a stable and remembered memory [14]. The amygdala-hippocampus-cortex interaction is also important for piecing together past sights, sounds, smells, and other contextual details into coherent narratives. These coherent narratives or stories, complete with contextual details, develop through coconstructions of past events with primary caregivers in early childhood. They are further refined during adolescence and constantly updated throughout life [13] and during the process of psychotherapy using ERs.

\section{Retrieval and reconsolidation: opportunities for movement and brain plasticity}

As mentioned above, the amygdala, in collaboration with the hippocampus and prefrontal cortex, plays a major role in online emotional processing. This collaboration also influences emotional memory retrieval, perhaps through re-experiencing emotion during the retrieval process [15]. Thus, the emotion experienced is also involved during memory retrieval. This might be why, when clients are asked to recall an ER during therapy, their current emotional state serves as a retrieval cue for a childhood memory that was consolidated due to a similar emotional arousal. An excellent way to find how clients perceive themselves is by using their ERs. Every ER is a complete metaphor that creatively describes the person's thoughts, wishes and feelings about their life in the present. The ERs are in constant movement and change, reflecting fluctuations in the person's current emotional state. One important theme of Adler's theory is the idea of movement, with Adlerian therapists encouraging their clients to move and use their creative power for a new movement forward. Adler compared the client to someone who is caught in a dark room and cannot find an exit. The therapist helps clients illuminate the room so they can move and find a way out - to new 
alternatives for dealing with current life problems. The movement or the opening of the client's view to new alternatives could be referred to as brain plasticity. As cited by Stein \& Stein [16], Adler said: "If we look back into our past and remember anything, we do not remember it in the way we were impressed at the time. It is especially easy to see ourselves in this remembrance as we have never seen ourselves in reality, which means we are continually reconstructing our memory" (p. 235).

Plasticity may occur during reconstruction of an ER. As mentioned above, retrieval of memories renders them transiently labile and susceptible to modification. This occurs due to the process of reconsolidation whereby the use of the client's creativity to change the memory might generate synaptic plasticity. Inserting new information into a retrieved memory, repeating the process several times and associating emotional arousal during the process may induce reconsolidation and, ultimately, a perceptual change. Neurological research [17-19] has supported the idea that new information resulting in increased intensity of a reactivation session can promote reconsolidation.

Example for the use of ER in Adlerian psychotherapy: We bring the case of a 55-year-old man who came to therapy complaining of not being loved and appreciated. He experienced emptiness and a lack of meaning in his life. The following memory (at age of seven) described those feelings:

"I remember going to bed at night. My mom was at home and I asked her to bring me a glass of water. My mother said, 'You had your glass of water already, now go to bed!'”

Focus: She tells me I had it already.

Feelings: I felt rejected, unloved, no one cares for me.

When asked to reconstruct the memory and tell it in a different way, the client devised various alternatives:

i. $\quad$ "I asked again and felt even worse."

ii. "I tried to think of my mother being very tired."

iii. "I got up and got myself a glass of water and felt good about it."

During the reconstruction process, the therapist and the client discussed the relevance of the metaphor for his current life. The client could easily identify himself as stuck in many life situations. He understood that when he expects to be served and does not initiate independent action, the result is his feeling stuck. This process of reconstruction needs to be repeated to create a gradual change in one's basic perceptions gradually. The client developed an ability to see the other person and focus less on himself. Adler (as cited in[2]) wrote, "Every individual represents both a unity of personality and the individual fashioning of that unity. The individual is thus both the picture and the artist" (p. 177). Therefore, if individuals can change their concepts of themselves, they can also change the pictures they are painting.
Memory is unstable after acquisition but progressively stabilized over time. As mentioned above, this stabilization process or synaptic consolidation encompasses a period of several hours [20-22]. Until relatively recently, it was believed that once consolidation is completed, memory is stored in a fixed state for as long as it persists [12,23]. Also, many scholars once viewed retrieval as simply a passive read-out of information encoded in the neuronal circuits supporting a long-term memory. This assessment was proven incorrect. Now it is known that retrieval can initiate an active process called reconsolidation. These newer studies have led to the interpretation that memory exists in two states: a labile or active state and a consolidated or inactive state. This notion changed the way modern science considers memory; as opposed to a stable, fixed entity, memory is dynamic and susceptible to modification when recalled $[17,19]$. The current conceptualization is that autobiographical memories are not stored as perfect records of specific events but constructed from our vast autobiographical knowledge. In addition, scholars now understand that multiple retellings of the same autobiographical event will not be identical and might differ depending on individuals' goals and motivations [10]. These findings show that neurological researchers only recently have uncovered the accuracy of Adler's revolutionary ideas stated 100 years ago.

\section{Relevance for psychotherapy}

Why is it essential for the therapist to understand and have full information about the brain function in relation to the use of ERs? The main purpose of Psychotherapy is to enable the client to change basic harmful perceptions. Neuro-scientific research investigates brain plasticity as a result of learning and experience [22]. Because cognitive change relies on changing brain structures, we assume that every Adlerian psychotherapist will benefit from understanding the correlation between therapeutic processes and brain functions. "Changing the mind" in the brain is a process of rewiring physical structures. This process affects behaviour and feelings. It is essential for Adlerian psychotherapists to be exposed to this important information in order to be more confident when using ERs in the therapeutic process. Understanding and employing the essential intervention of ER reconstruction can enable change.

Adler said that the emotions associated with the ERs are currently felt in the present. Neurological research, reviewed by Holland \& Kensinger [14], has shown that emotions and feelings associated with early recollections are metaphors of current events. People tend to conceptualize life according to previous experiences and often do not allow movement from these to new ones. The main goal of psychotherapy is to enable change and movement. Understanding the concept of movement in the brain and in ERs provides an optimistic message for the therapist. That both are in a state of constant change means change can occur during therapy. The golden moment for change occurs during the process of continuous ER reconstruction and in repetition of 
this process. Reconstruction of ERs induces rewiring of the brain synapses and thus behaviour and feelings.

\section{Conclusion}

Using ERs is crucial not only to understand the person's Life Style and private logic, but mainly also to trigger movement and change through the process of ER reconstruction and reconsolidation, as validated by the latest neuro-scientific research [9,17-19].

\section{Acknowledgment}

We would like to express our sincere appreciation to Paola Prina (London), Karen John (Bath, Avon) and Anthea Millar (Cambridge) for their careful reading and thoughtful comments and for editing this paper for the British Adlerian Yearbook.

\section{References}

1. Miller R, DD Taylor (2016) Does Adlerian Theory Stand the Test of Time? Examining Individual Psychology from a Neuroscience Perspective. The Journal of Humanistic Counseling 55(2): 111-128.

2. Ansbacher HL, Ansbacher RR (1956) The individual psychology, a systematic presentation in selections from his writings: Edited and annotated by Heinz L, Ansbacher, Rowena R, Ansbacher. Basic Books, New York, USA.

3. Shifron R, BL Bettner (2003) Using early memories to emphasize the strengths of teenagers. The journal of individual psychology 59(3): 334-343.

4. Shifron R (2008) Coping with Change: An Adlerian Model. Adlerian Year Book, United Kingdom p.70-78.

5. Shifron R, BL Bettner (2017) Framing a couple's new contract through early recollections. UK Adlerian Year book, United Kingdom p.54-92.

6. LeDoux J (2003) The self: clues from the brain. Ann N Y Acad Sci 1001: 295-304.

7. Elroy P, Weledji, Ciaran M Regan (2014) The Neuroanatomical Localization of a Specific Memory. International Journal of Brain and Cognitive Sciences 3(2): 44-49.

8. Squire LR, ER Kandel (2000) Memory: From Mind to Molecules. Henry Holt and Company, United States.
9. Luo L (2015) Chapter 10 -Memory, learning, and synaptic plasticity. Principles of Neurobiology Garland Science, p.464.

10. Conway M, D Rubin (1996) The structure of autobiographical memory. In: Collins, AF Gathercole, SE, Conway MA, Morris PE (Eds.), Theories of memory. Hillsdale, Erlbaum, New Jersey, US State, p. 103.

11. Kant I (2006) Kant: Anthropology from a Pragmatic Point of View. (Original work published 1798), Cambridge University Press. Cambridge, United Kingdom.

12. McGaugh JL (2013) Making lasting memories: remembering the significant. Proc Natl Acad Sci U S A, 110 (Suppl 2): 10402-10407.

13. Dornelles A, Arethuza D, Maria N Martins de Lima, Manoela G, Juliana $P$, et al. (2007) Adrenergic enhancement of consolidation of object recognition memory. Neurobiol Learn Mem 88(1): 137-142.

14. Holland AC, EA Kensinger (2010) Emotion and Autobiographical Memory. Physics of life reviews 7(1): 88-131.

15. Buchanan TW (2007) Retrieval of Emotional Memories. Psychol Bull 133(5): 761-779.

16. Stein HT, LJ Stein (2012) A Clinician's Guide to the Collected Clinical Works of Alfred Adler: A Unified System of Depth Psychotherapy, Philosophy, and Pedagogy. Alfred Adler Institute of Northwestern Washington, Bellingham, US State.

17. Haubrich J, K Nader (2016) Memory Reconsolidation. Curr Top Behav Neurosci 37:151-176.

18. Paulson S, Aciman A, Ledoux J, Schacter D, Winter A (2013) The mystery of memory. In: search of the past. Ann N Y Acad Sci 1303: 36-55.

19. Schiller D, CM Raio, EA Phelps (2012) Extinction training during the reconsolidation window prevents recovery of fear. J Vis Exp 2012(66): p.e3893.

20. Dudai Y, R Morris (2000) To consolidate or not to consolidate: what are the questions? , ed. p. In: Bolhius J (ed) Brain, memory: advances in cognitive sciences. Oxford Press, United Kingdom.

21. Kandel ER (2001) The Molecular Biology of Memory Storage: A Dialogue Between Genes and Synapses. Science 294(5544): 10301038.

22. Martin SJ, PD Grimwood, RG Morris (2000) Synaptic plasticity and memory: an evaluation of the hypothesis. Annu Rev Neurosci 23: 649711.

23. Squire LR, NH Cohen, L Nadel (1984) The Medial Temporal Region and Memory Consolidation: A New Hypothesis. . Memory Consolidation. Erlbaum, Hillsdale, New Jersey, US State.

This work is licensed under Creative Commons Attribution 4.0 License DOI:10.19080/PBSIJ.2020.15.555908

\section{Your next submission with Juniper Publishers will reach you the below assets}

- Quality Editorial service

- Swift Peer Review

- Reprints availability

- E-prints Service

- Manuscript Podcast for convenient understanding

- Global attainment for your research

- Manuscript accessibility in different formats

( Pdf, E-pub, Full Text, Audio)

- Unceasing customer service

Track the below URL for one-step submission https://juniperpublishers.com/online-submission.php 